This Chapter appears in the book Renewable Energy in the Service of Mankind Vol II. Selected Topics from the World Renewable Energy Congress WREC 2014, Ed. A. Sayigh, Springer International

Publishing 2016, p.393-402. doi:10.1007/978-3-319-18215-5 35

\title{
PV cell and module degradation, detection and diagnostics
}

\author{
Eleni Kaplani \\ RES Lab, Mechanical Engineering Dept., Technological Educational Institute of Western Greece, \\ Meg. Alexandrou 1, Patra-26334, Greece \\ ekaplani@teiwest.gr
}

\begin{abstract}
With crystalline silicon photovoltaic (PV) modules being on the market for over 3 decades, investigation into usual causes and extent of module degradation after prolonged exposure in field conditions is nowadays possible. Degradation phenomena vary significantly between cells, modules and installations, giving rise to different power degradation rates reported. The main defects that have been observed in field aged PV modules, include EVA browning, degradation of the anti-reflective coating, delamination between the glass-encapsulant and the cell-encapsulant interfaces, humidity ingress, corrosion of busbars and contacts, shunt paths, cracks/ micro-cracks in the cell, damage of the glass and the back sealing, and bypass diode failure. This study presents severe degradation effects observed in PV modules operating outdoors for over 20 years. In many of the cases investigated different defects were seen to coexist within the same cell or module, leading to more severe effects of optical/physical, thermal, and electrical degradation phenomena significantly reducing the PV power output. Other modules which exhibited extensive optical/physical degradation showed milder degradation in performance. Detection of module degradation was carried out in this study first through visual inspection and I-V curve analysis. Further non-destructive diagnostic techniques were used such as infrared thermography for the identification of hot spots, that were seen to be mainly linked to resistive busbars and contacts, and electroluminescence imaging for the identification of shunts and other defects. The detection, diagnosis and monitoring of such defects is of great importance for a deeper understanding of the complex ageing mechanisms that take place after prolonged $\mathrm{PV}$ exposure in field conditions, and the identification of underlying causes, assisting the early identification of defects and the extension of the energy life of PV systems.
\end{abstract}

Keywords: PV degradation, diagnostics, infrared thermography, electroluminescence

\section{Introduction}

A deeper understanding of degradation mechanisms that take place from the very early to the late stages of PV module life during outdoor operation is essential for a more accurate estimation of module lifetime and prognosis of possible future faults. The PV module qualification tests, as for instance the IEC 61215 for crystalline silicon PV modules, are based on accelerated stress tests such as thermal cycling, damp heat test, humidity-freeze cycling, UV test, static and dynamic mechanical load test, hot spot test, etc, in an attempt to replicate failure modes that may be observed in the field. These tests identify design and material faults that would lead to premature field failure, but do not address failure mechanisms or quantify lifetime for the intended application, system configuration and climate [1]. Thus, studies on PV module operation in field conditions for many years can provide valuable information on the reliability and durability of PV modules in real life. A review on PV degradation rates reported in the literature from field testing, gave a skewed distribution with a mean degradation of $0.8 \%$ per year and a median of $0.5 \%$ per year, with $78 \%$ of the data reported having a degradation rate below $1 \%$ per year [2]. Initial rapid light-induced degradation accounts for a $1-5 \%$ loss in short circuit current [3].

In this study, degradation phenomena observed in PV modules operating in the field for up to 25 years will be presented. Non-destructive diagnostic techniques including I-V curve analysis, infrared thermography and electroluminescence are employed here to assess PV performance and identify the defects. Modules that have undergone different stages of degradation, from initial rapid lightinduced degradation, to mild and severe degradation phenomena are analysed, and degradation 
estimates are given for several of these modules tested revealing the need for a deeper understanding of PV degradation phenomena that occur under real conditions of operation.

\section{Diagnostic techniques}

Visual inspection is a simple and significant procedure for the identification of defects and early signs of module failure mechanisms. A close examination of PV modules can reveal early signs of browning of the ethylene-vinyl-acetate (EVA) encapsulant, degradation of the anti-reflective (AR) coating, delamination, cracks in the cells, burn marks, etc. Illumination of the cells with UV light at $375 \mathrm{~nm}$ can assist the identification of EVA browning [4]. Fig. 1 shows the digital image of a cell with mild browning of the EVA and the UV illuminated image where the EVA browning is clearly revealed making possible the assessment and monitoring of the extent of the browning. This may also be achieved through digital image processing [5].

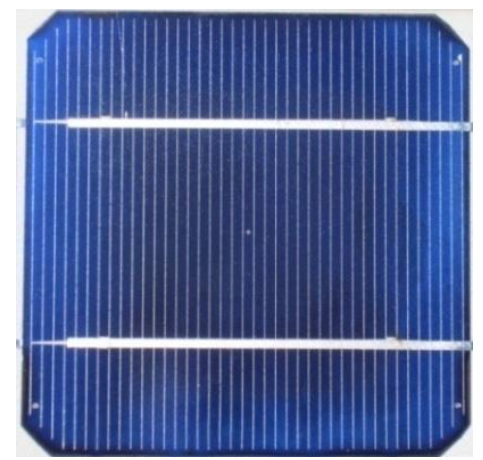

(a)

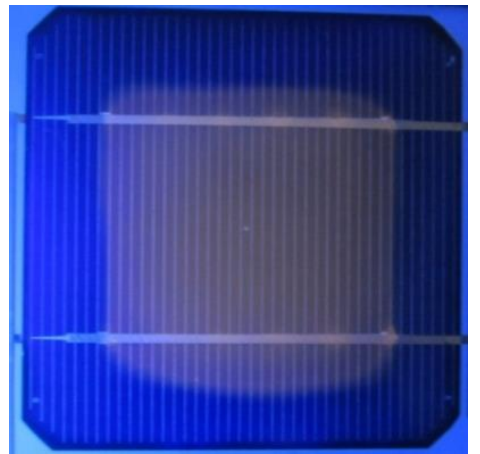

(b)

Fig.1(a) digital image of PV cell with mild EVA browning, (b) the same cell illuminated with UV light. The module operates outdoors in the RES Lab for 20 years.

Infrared (IR) thermography is a powerful tool for the location of defected cells or cell areas that exhibit higher or lower localised temperature than the remaining part of the module or cell respectively. Fig.2(a) shows the IR image of several modules of a PV generator operating in field conditions for 20 years. The IR image is captured by means of an IR camera with spectral range 7.5 to $14 \mu \mathrm{m}$. Hot cells operating in temperatures of $20^{\circ}$ to $30^{\circ} \mathrm{C}$ higher than the average temperature of the remaining part of the module are visible. Such large temperature differences signify defected cells. IR thermography may also be taken in the dark with the module forward-biased using a DC power supply. Fig.2(b) shows a sc-Si PV module with 20 year outdoor operation tested in the lab. The IR image reveals two cells having a hot spot at the busbar. By reverse-biasing the module in the dark it is possible to check diode functionality. Fig.2(c) shows the IR image of a flexible a-Si PV module with bypass diodes connected across each of the 11 cells, and Fig.2(d) shows the junction box of a pc-Si PV module reverse-biased showing the operation of the three diodes.

Electroluminescence (EL) imaging is a sensitive technique for deeper investigation into failure causes, assisting in the identification of cracks, broken metallization, regions of higher resistance and shunts [6]. It is carried out in the dark with the PV module in forward-bias mode, and is based on the light emission of the PV module at around $1150 \mathrm{~nm}$ as a result of the radiative recombination of carriers. A NIR sensitive Si-CCD or SWIR camera is required. A SWIR camera with InGaAs sensor and spectral range from 0.9 to $1.7 \mu \mathrm{m}$ was used in this study for the EL image capture. A contactless diagnostic technique with the module at open-circuit mode, which involves SWIR image capture is Photoluminescence (PL). It is based on the photoluminescence emission due to radiative recombination after optical excitation with light at $800 \mathrm{~nm}$. Additional information may be obtained through separation of band-to-band emission images at around $1150 \mathrm{~nm}$ from the defect-band emission images at around $1550 \mathrm{~nm}$ using cut-off filters [7].

Microscopic techniques such as Scanning Electron Microscopy (SEM), including Electron Beam Induced Current (EBIC), Energy-Dispersive X-ray analysis (EDX), Transmission Electron Microscopy (TEM) can assist in the in-depth investigation of the physical defects, such as different types of shunts [8]. Destructive techniques require a proper dissection of the laminated PV module which is a difficult task. 


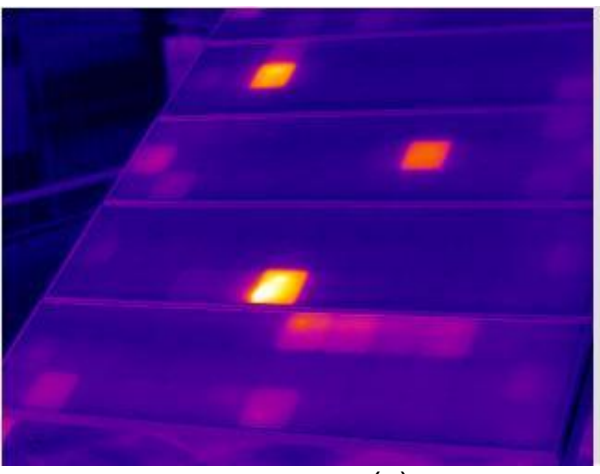

(a)

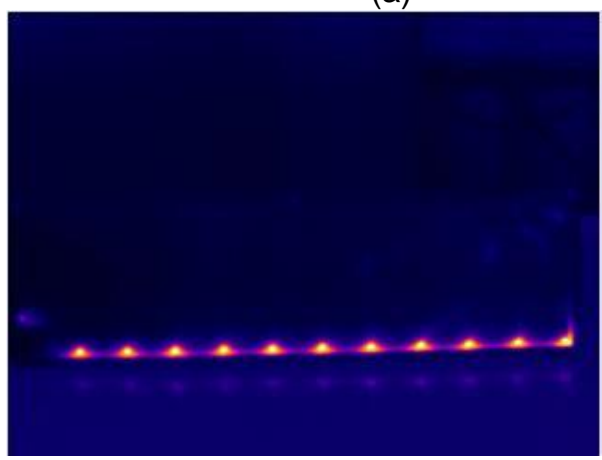

(c)

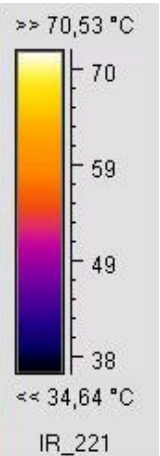

$>61,05^{\circ} \mathrm{C}$

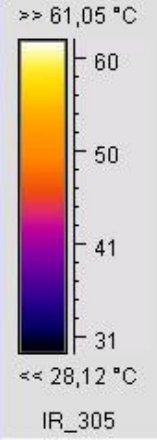

R_305

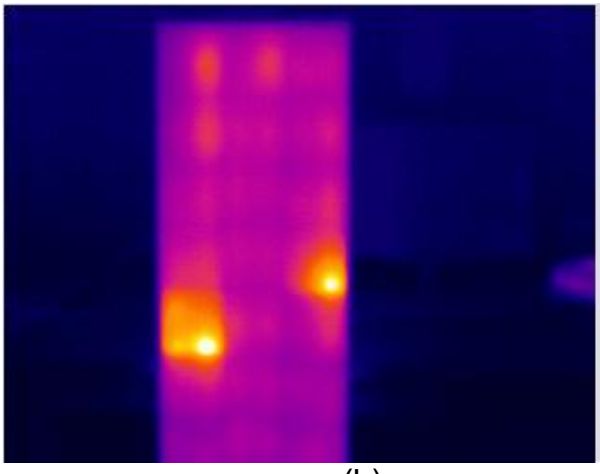

(b)

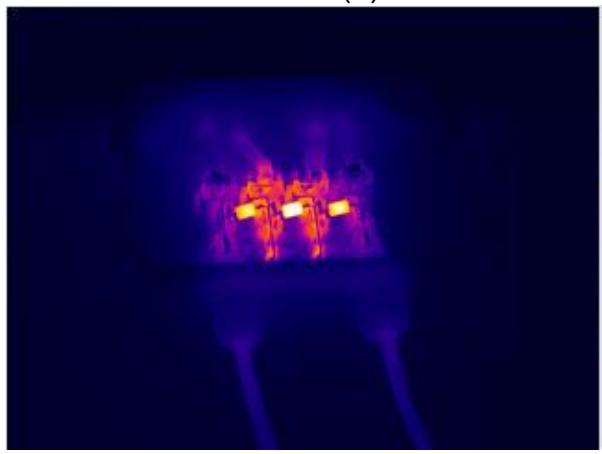

(d)
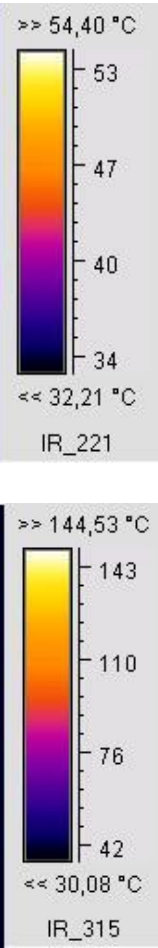

IR_315

Fig.2. Infrared thermography of (a) a Sc-Si PV generator operating at load in the RES Lab for 20 years, (2) a sc-Si PV module forward-biased in the dark within the lab, (c) a flexible a-Si PV module reverse-biased in the lab, (d) the junction box of a pc-Si PV module reverse-biased in the lab.

\section{Degradation phenomena}

Degradation phenomena observed in the PV modules operating outdoors for several years in the RES Lab include discoloration of the EVA with different patterns and yellowness index (Fig.3(a),(b),(c),(d)), degradation of the AR coating with different degree of severity (Fig.3(b),(c),(d)), degradation of the cell-encapsulant interface between the gridlines in the proximity of the busbars (Fig.3(b)) and in a flexible a-Si PV module in the form of delamination (Fig.3(f)). Furthermore, corrosion and burn marks were observed mainly on the busbars and cell interconnections, usually also visible at the back side of the module together with bubbles, cracks, and tears of the Tedlar (Fig.3(d),(e)). Finally, broken cells, micro-cracks and interrupted gridlines (Fig.3(g),(h)) were also observed.

\section{PV degradation and diagnosis}

Several modules that have been operating outdoors in the RES Lab from only several hours up to 25 years have been examined. Defect detection and diagnosis has been carried out via means of visual inspection, digital image with UV light illumination, I-V curve analysis, IR thermography and electroluminescence.

The visual inspection of a new sc-Si PV module that has operated outdoors only for several hundred hours and has experienced initial rapid light-induced degradation, has revealed slight deterioration of the cell-encapsulant interface at the proximity of the busbar (Fig.4(a)). Electroluminescence with the module forward-biased at near $\mathrm{V}_{\mathrm{oc}}$, revealed a crack in one cell with a large region appearing dark in the EL image (Fig.4(b)). The EL image of part of the module reveals several grid finger interruptions and a rather inhomogeneous EL emission in some cells (Fig.5(a)). The IR thermography revealed some cells exhibiting about $10^{\circ} \mathrm{C}$ higher temperature than the average temperature of the module, 
while some correlations between the IR image and EL image were observed (Fig.5(b)). I-V curve analysis and translation to Standard Test Conditions (STC), gave a 3.7\% reduction in power output.

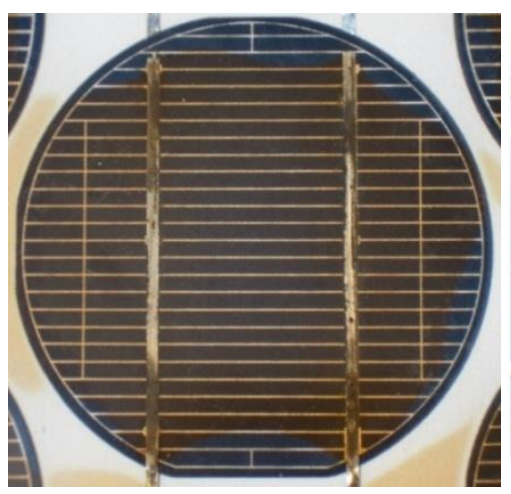

(a)

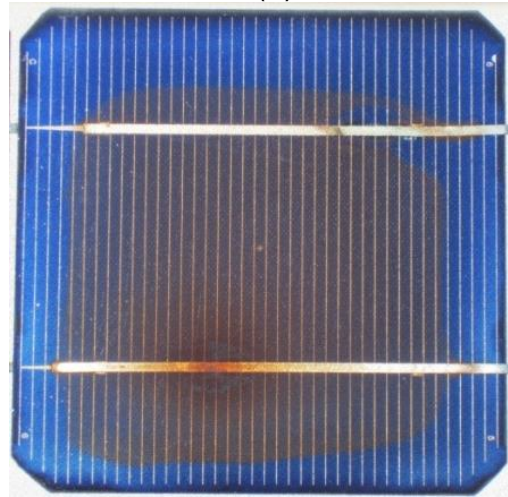

(d)

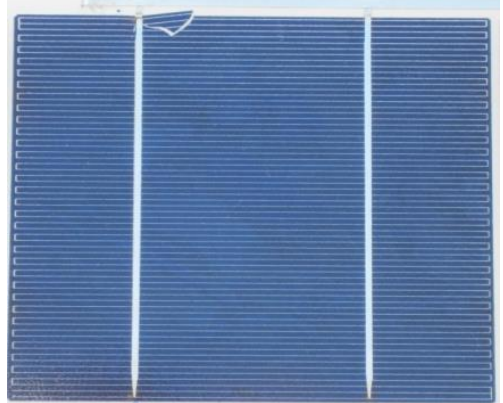

(g)

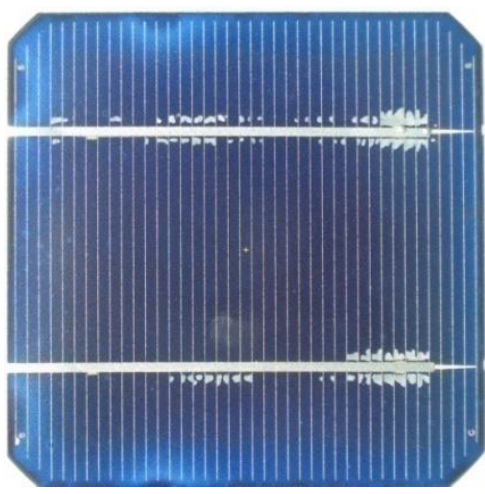

(b)

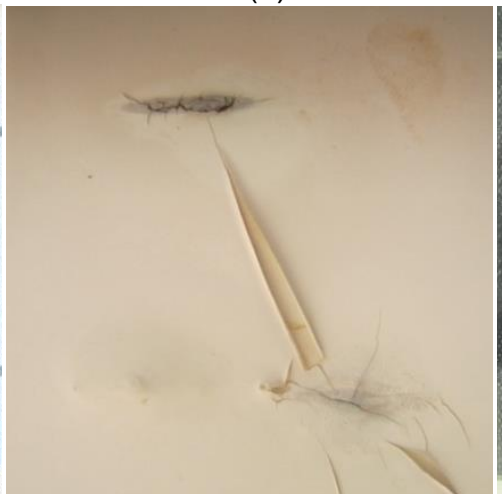

(e)
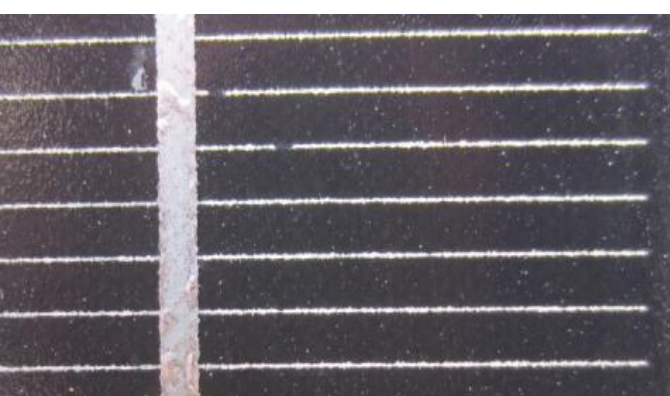

(h)

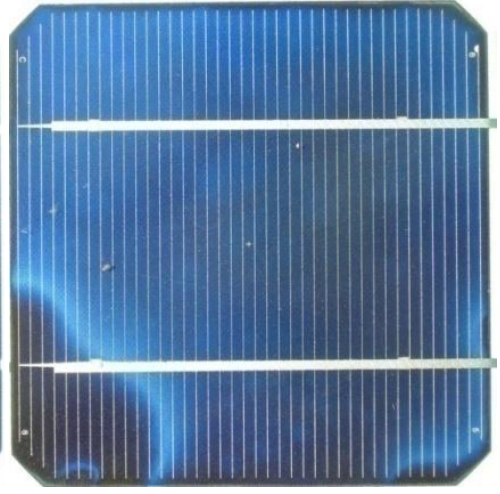

(c)

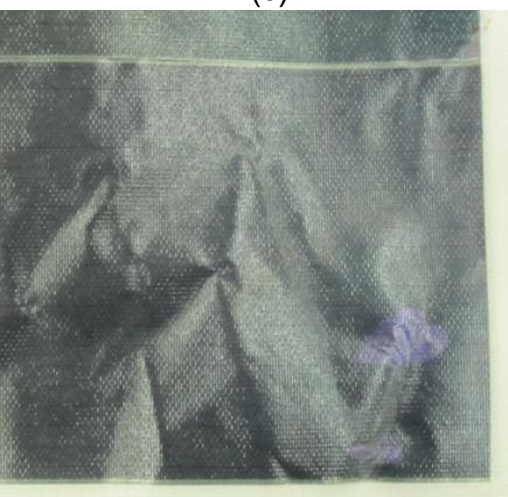

(f)

Fig.3. Degradation phenomena observed in PV modules operating outdoors in the RES Lab, (a) EVA browning, (b) deterioration of the cell-encapsulant interface and other effects, (c) degradation of the AR coating and other effects, (d) corrosion, burn mark, EVA browning and other effects, (e) corrosion, burn marks, tear and bubble at the back of the module, (f) delamination in a flexible a-Si module, $(\mathrm{g})$ broken cell, $(\mathrm{h})$ broken gridlines.
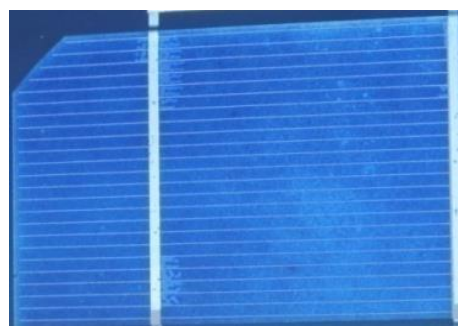

(a)

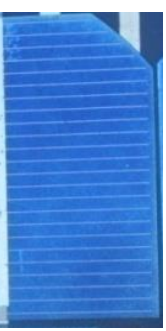

Fig.4. A new sc-Si PV module with only several hundred hours of outdoor operation in the RES Lab. (a) digital image of a cell exhibiting slight deterioration in the cell-encapsulant interface, (b) EL image of the same cell revealing a crack.

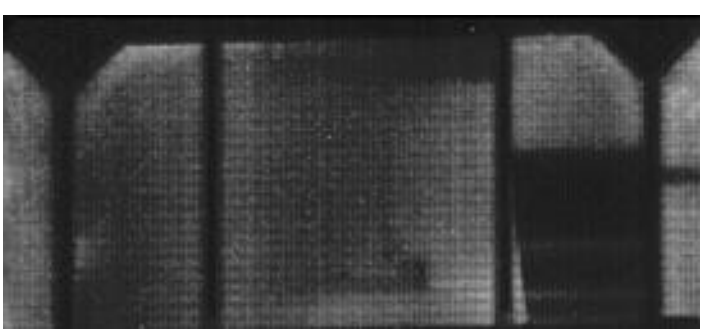

(b) 


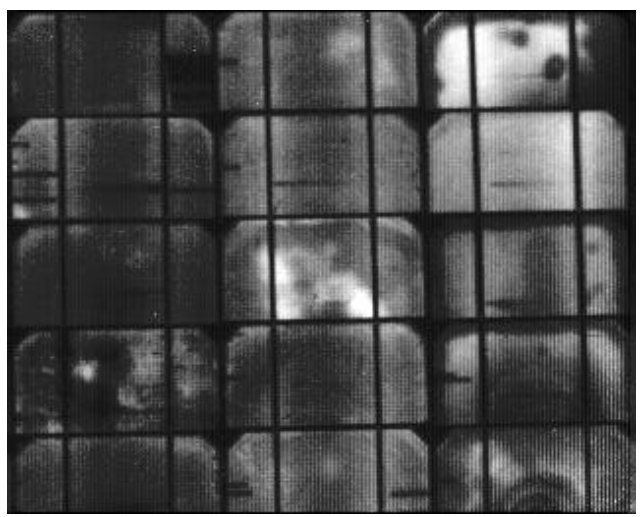

(a)

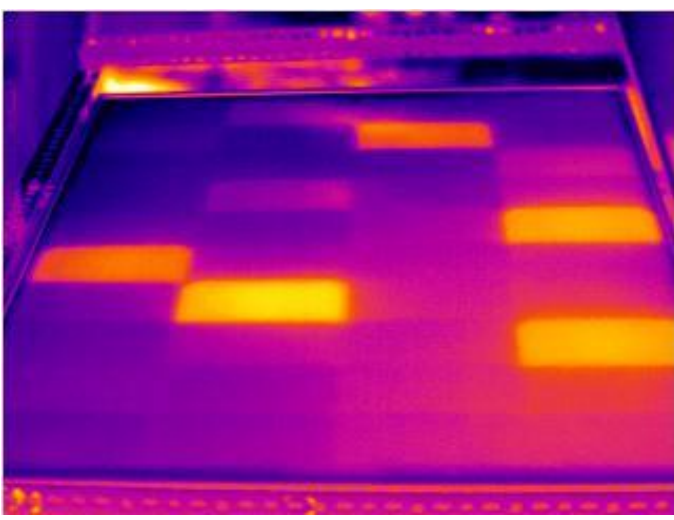

(b)

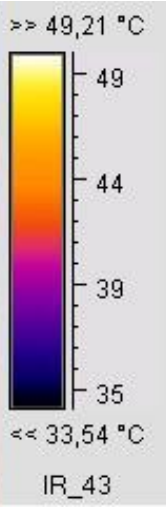

R_43

Fig.5. Image from part of a new sc-Si PV module with only several hundred hours of outdoor operation in the RES Lab, (a) EL image (b) IR image.

A sc-Si PV module operating outdoors for 15 years exhibits mild signs of AR deterioration and degradation in the cell-encapsulant interface at the proximity of the busbars, see Fig.6. IR thermography shows a rather uniform temperature distribution of the module with only one cell exhibiting higher temperature by about $10^{\circ} \mathrm{C}$ from the average temperature of the module, Fig.7(a). EL imaging further reveals cells with several interrupted grid lines, Fig.7(b).

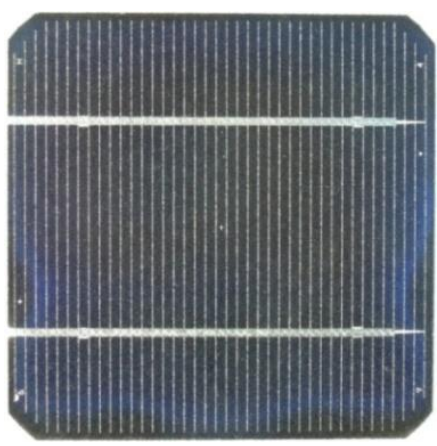

(a)

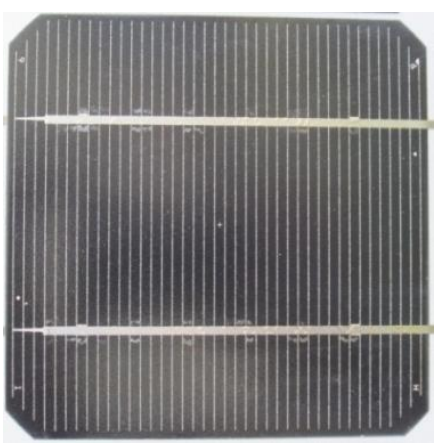

(b)

Fig.6. sc-Si PV module operating outdoors in the RES Lab for 15 years exhibiting mild signs of degradation of the (a) AR coating, (b) the cell-encapsulant interface.

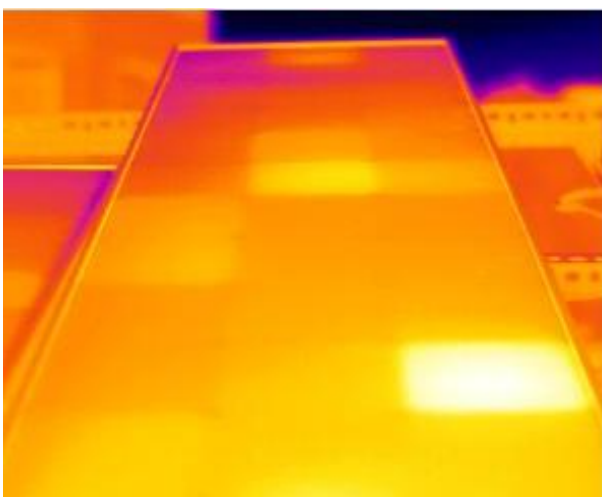

(a)

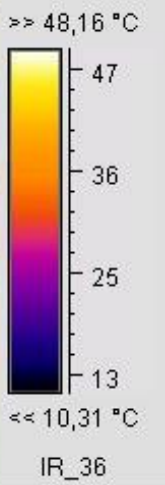

R_36

Fig.7. sc-Si PV module operating outdoors in the RES Lab for 15 years exhibiting mild signs of degradation (a) IR image (b) EL image of one of the cells

Several Sc-Si PV modules operating in the RES Lab for 20 years have experienced degradation through induced shading effects for a prolonged period of several months [5]. These modules now exhibit severe optical and electrical degradation phenomena mainly associated to the affected cells 
[9]. As an example, the IR image of one of these modules reveals a hot cell with a hot spot on the busbar exhibiting a temperature difference greater than $40^{\circ} \mathrm{C}$ from the average temperature of the module, Fig.8(a). The cell and spot temperature exceeds $100^{\circ} \mathrm{C}$, which is detrimental for the operational life of the cell and module. The EL image of part of this module (Fig.8(b)) reveals inhomogeneous EL emission, several interrupted gridlines, shunts and microcracks.

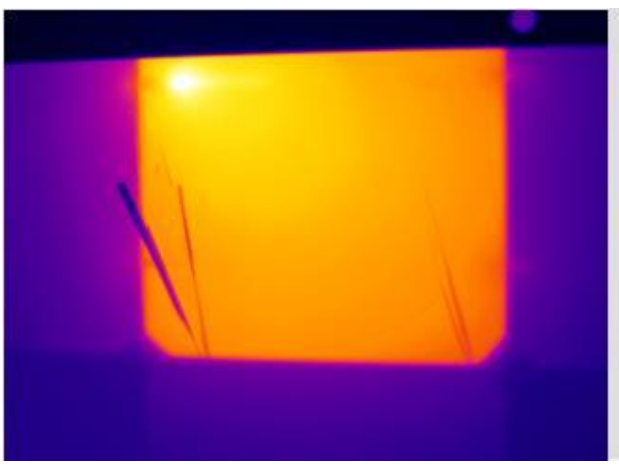

(a)

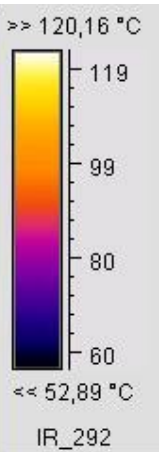

IR_292

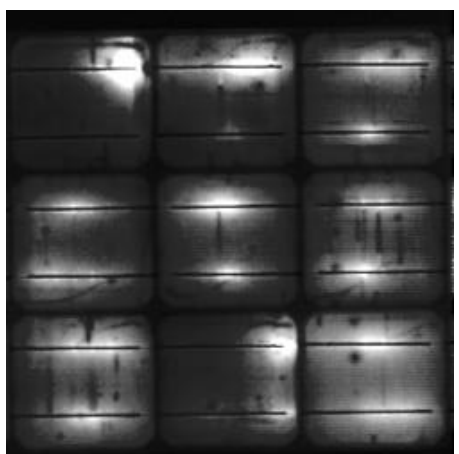

(b)

Fig.8. sc-Si PV module operating outdoors for 20 years, (a) IR image at the back side of the module at the hot cell, (b) EL image of part of the module.

Other sc-Si PV modules operating outdoors in the RES Lab for 24 and 25 years, and have aged naturally, exhibit a rather uniform temperature distribution (Fig.9(a)). Further investigation through electroluminescence reveals the existence of cracks in several cells, some of which isolate a part of the cell, inactive areas and inhomogeneous EL emission, Fig.9(b),10.
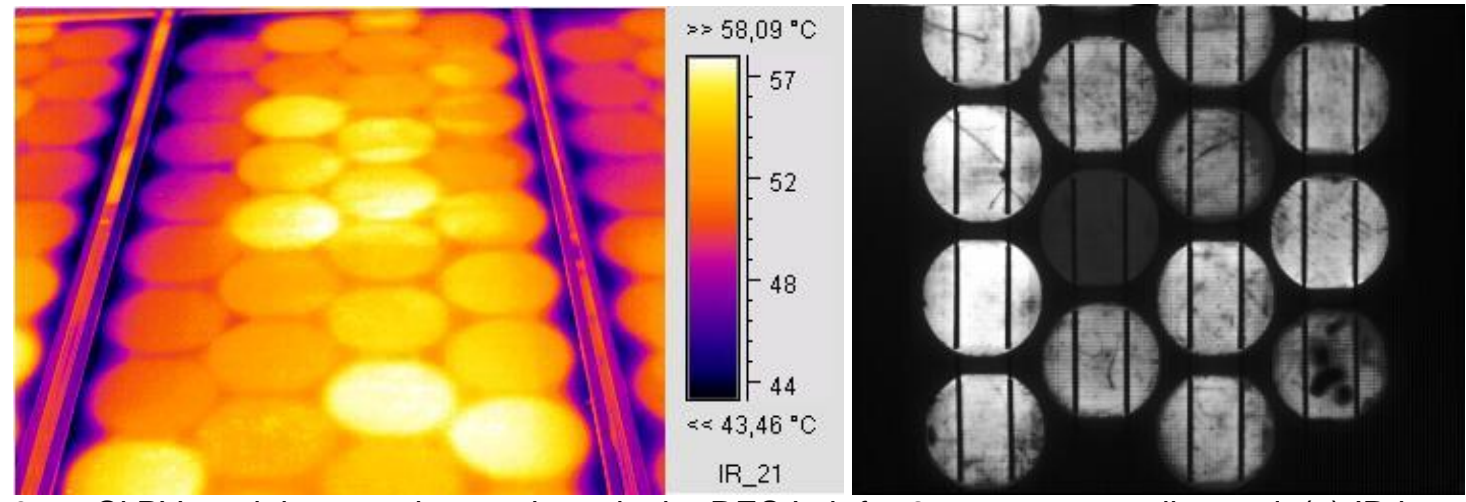

Fig.9. sc-Si PV module operating outdoors in the RES Lab for 25 years -naturally aged, (a) IR image, (b) EL image.
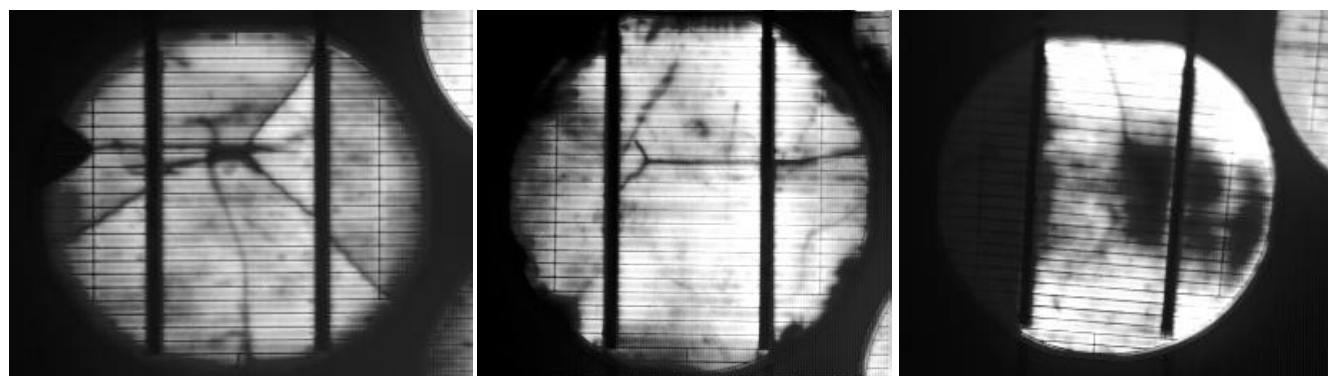

Fig.10. EL image of cells from the module in Fig.9 exhibiting cracks

\section{PV degradation estimates}

An estimate of the degradation of the 20 and 25 year old PV modules experiencing induced and natural ageing respectively is carried out through I-V curve analysis. The STC normalised I-V curves of the modules that experienced induced shading effects in the past are displayed in Fig.11(a). Large deviations in the I-V curve characteristics are observed in this modules, some of which reveal the 
existence of some optically degraded cells, while others reveal an increased series resistance due to corrosion, as regarded in the slope of the curve at open circuit voltage. The relative reduction in power output ranges between $25 \%-41 \%$, in the short circuit current $6 \%-15 \%$, in the open circuit voltage $3 \%-5 \%$ and in the fill factor $12 \%-34 \%$. On the other hand, the naturally aged $24-25$ year-old modules have non-deformed I-V curve characteristics, with relative reduction in the fill factor of only $4 \%-5 \%$. The relative reduction in power output ranges between $20 \%-25 \%$, which is mostly attributed to the short circuit current with a relative reduction of $13 \%-15 \%$. This is only partly due to the optical losses caused by the severe EVA browning that affects all cells of the module (Fig.3(a)), but is also due to the several cracks and inactive areas in the cells revealed by the EL image. The reduction in the open circuit voltage is in the range of $5 \%-7 \%$.

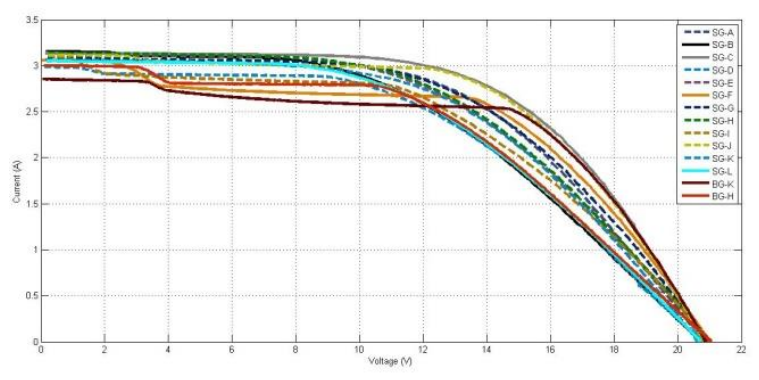

(a)

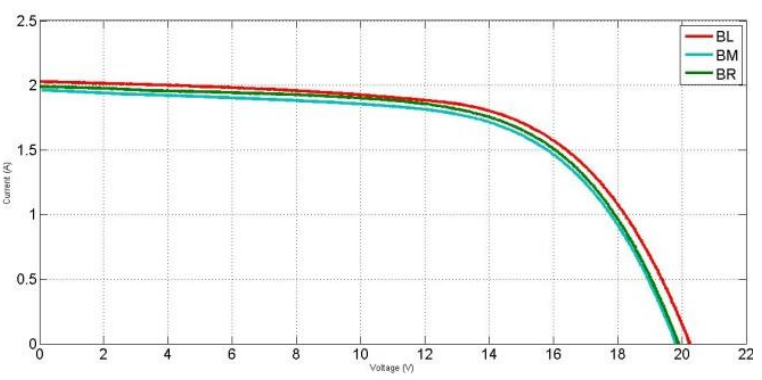

(b)

Fig.11. STC normalised I-V curves (a) 20 year-old modules with induced shading effects, (b) 24-25 year-old modules with natural ageing.

\section{Conclusions}

The ageing of PV modules is a complex process that may involve a cascade of events based on different effects caused by a chain of chemical reactions. It was shown to significantly differ between modules and cells of the same module. Several modules operating outdoors from several hours to as many as 25 years have been examined and defect detection and diagnosis was carried out through visual inspection, also with the assistance of UV light illumination, I-V curve analysis, IR thermography and electroluminescence. A combination of all these techniques was found important for an in-depth analysis of PV degradation and underlying defects. Furthermore, electroluminescence imaging gave significant insights to the actual physical condition of the modules, especially in cases where I-V curve analysis and IR thermography did not show abnormal behaviour due to the uniformity of the effects within the module. IR thermography and EL imaging can serve as important tools not only for diagnosis but also for the prognosis of possible future defects in the modules.

\section{References}

[1] J. Wohlgemuth (2012). IEC 61215: What it is and isn't. 2012 PV module Reliability Workshop. NREL/PR5200-54714.

[2] D.C. Jordan, S.R. Kurtz (2012). Photovoltaic Degradation Rates -An Analytical Review.NREL/JA-5200-51664.

[3] V. Sharma, S.S.Chandel (2013). Performance and degradation analysis for long term reliability of solar photovoltaic systems: A review. Renewable and Sustainable Energy Reviews, 27, pp.753-767.

[4] E.L.Meyer, E.E. van Dyk (2004). Assessing the reliability and degradation of photovoltaic module performance parameters. IEEE Transactions on Reliability, Vol.53(1), pp.83-92.

[5] E. Kaplani (2012). Detection of degradation effects in field-aged c-Si solar cells through IR thermography and digital image processing. International Journal of Photoenergy. Vol.2012, Art.no.396792, p.1-11, doi:10.1155/2012/396792.

[6] M. Sander, B. Henke, S. Schweizer, M. Ebert, J. Bagdahn (2010). PV module defect detection by combination of mechanical and electrical analysis methods. Proc. IEEE 35th Photovoltaic Specialists Conference, 20-25 June 2010, Honolulu.

[7] F. Yan, S. Johnston, M. Al-Jassim, K. Zaunbrecher, O. Sidelkheir, A.Blosse (2011). Defect-band emission photoluminescence imaging on multi-crystalline Si solar cells. Proc. 37th IEEE Photovoltaic Specialists Conference, June 19-24 2011, Seattle, Washington. NREL/CP-5200-50725.

[8] O.Breitenstein, J.P.Rakotoniaina, M.H. Al Rifai, M.Werner (2004). Shunt types in crystalline silicon solar cells. Progress in Photovoltaics: Research and Applications, Vol.12,pp.529-538.

[9] E. Kaplani (2012). Degradation effects in sc-Si PV modules subjected to natural and induced ageing after several years of field operation. Journal of Engineering Science and Technology Review, Vol. 5 (4), pp.18-23. 